\title{
Flora das Cangas da Serra dos Carajás, Pará, Brasil: Amaranthaceae
}

Flora of the cangas of Serra dos Carajás, Pará, Brazil: Amaranthaceae

Luiza Ramos Senna ${ }^{1,3}$ \& Carla Teixeira de Lima ${ }^{2}$

\begin{abstract}
Resumo
Este estudo engloba as espécies de Amaranthaceae registradas para as cangas da Serra dos Carajás, no estado do Pará, trazendo descrições detalhadas, ilustração e comentários morfológicos das espécies. São registradas quatro espécies, sendo duas do gênero Alternanthera Forsk. e duas espécies do gênero Cyathula Blume, para a área de estudo.

Palavras-chave: Alternanthera, Cyathula, florística.
\end{abstract}

\begin{abstract}
This study comprises the species of Amaranthaceae registered for the cangas of Serra dos Carajás, Pará state, including detailed descriptions, illustrations and morphological comments of the species. Four species are registered for the study area: two species of Alternanthera Fork. and two species of Cyathula Blume.

Key words: Alternanthera, Cyathula, floristics.
\end{abstract}

\section{Amaranthaceae}

As Amaranthaceae Juss. são ervas, arbustos ou subarbustos. Possuem folhas simples, sem estípulas, margem inteira, serreada ou lobada, glabras ou indumentadas. As inflorescências são em espigas capituliformes, espiciformes, racemos ou panículas, unidade parcial da inflorescência em dicásio que pode ser reduzido a uma única flor, ou apresentar flores laterais muito reduzidas ou modificadas. Suas flores são pequenas, bissexuadas ou unissexuadas, monoclamídeas, com 3-5 tépalas, livres ou unidas na base, escariosas, paleáceas ou membranáceas; androceu geralmente isostêmone, filetes livres ou unidos em tubo estaminal, alternandos ou não com pseudoestaminódios; anteras bitecas ou monotecas; gineceu com 2-3 carpelos unidos formando um ovário unilocular,
1 óvulo basal (multiovulado em Celosia L.) (Kühn 1993; Towsend 1993; Cronquist \& Thorne 1994; Kadereit et al. 2004). Inclui 180 gêneros e 2.500 espécies distribuídas nas faixas tropicais e temperadas dos dois hemisférios (APG IV 2016; Townsed 1993; Künh 1993).

No Brasil, a família é representada por 27 gêneros e cerca 158 espécies (BFG 2015). Na Serra dos Carajás foi registrada quatro espécies para família: Alternanthera dentata (Moench) Stuchlik ex R.E. Fr., A. tenella Colla, Cyathula achyranthoide (Kunth) Moq. e C. prostrata Blume, a espécie Chamissoa altissima (Jacq.) Kunth é uma planta que ocorre em área de mata foi coletada nos bordos de matas próximas que circundam as regiões de canga na Serra dos Carajás, não pertencendo assim à área de estudo.

\section{Chave de identificação dos gêneros de Amaranthaceae das cangas da Serra dos Carajás}

1. Inflorescência em dicásios perfeitos, sendo as flores laterais estéreis, essas com as tépalas modificadas em 8-20 cerdas unguiculadas; anteras bitecas, tetraesporangiadas Cyathula

1'. Inflorescência em dicásios reduzidos a uma única flor; anteras monotecas, biesporangiadas.

\footnotetext{
${ }^{1}$ Instituto Federal da Bahia - IFBA, Campus Feira de Santana, Rod. BR 324, Km 102.11 s/n, Aviário, 44135-000, Feira de Santana, BA, Brasil

${ }^{2}$ Instituto Tecnológico Vale de Desenvolvimento Sustentável, R. Boaventura da Silva 955, 66055-090, Nazaré, Belém, PA, Brasil.

3 Autora para correspondência: luisasenna@ifba.edu.br
} 


\section{Alternanthera Forsk.}

As espécies de Alternanthera tem folhas opostas, inflorescências axilares, com unidade parcial do tipo dicásio, com uma bráctea dorsal e duas bractéolas laterais, reduzido a uma única flor fértil, bissexuada, raramente com par de flores laterais diminutas inférteis (A. philoxeroides (Mart.) Griseb). As flores possuem 5 tépalas, livres ou fundidas na base, paleáceas ou escariosas, 3-5 estames com filetes unidos em tubo curto e com porções livres alternadas com pseudo-estaminódios, anteras monotecas, biesporangiadas, estigma capitado, estilete curto ou longo, fruto utrículo indeiscente (Senna 2015).
O gênero tem distribuição pantropical, com centro de diversidade nas regiões semi-áridas americanas, especialmente na região central dos Andes (Equador, Peru e Bolívia), no subpuna (Argentina e Bolívia), desertos dos Estados Unidos e México e no Brasil (Townsend 1993; Senna et al. 2010). O gênero Alternanthera inclui cerca de 100 espécies neotropicais (Townsend 1993; Pino et al. 2012). No Brasil, o gênero compreende 36 espécies, sendo 12 endêmicas, distribuídas em todos domínios fitogeográficos e entre quase todos os tipos vegetacionais encontrados (BFG 2015).

\section{Chave de identificação das espécies de Alternanthera das cangas da Serra dos Carajás}

1. Arbusto ou subarbusto, decumbente a subescandente; folhas com pecíolo maior que $0,5 \mathrm{~cm}$ de comprimento; inflorescências pedunculadas; flores subtendidas pelo conjunto de bractéolas, com tépalas iguais entre si . 1.1. Alternanthera dentata

1'. Subarbusto ereto ou prostrado; folhas com pecíolo $0,1-0,2 \mathrm{~cm}$ de comprimento; inflorescências sésseis; flores sobressaindo acima da altura das bractéolas, com tépalas desiguais entre si.

1.2. Alternanthera tenella

1.1. Alternanthera dentata (Moench) Stuchlik ex R.E. Fr. Ark. Bot. 16(13): 11-12. 1921.

Fig. 1a-b

Arbusto ou subarbusto, decumbente a subescandente, ca. $1 \mathrm{~m}$ alt. Folhas pecioladas, pecíolo 0,6-1,3 cm compr.; limbo foliar 1,2-7 cm compr., 1,8-2,3 cm larg., elíptico, membranáceo, concolor, verde, glabro em ambas as faces, broquidódromo, base cuneada, margem inteira, ápice agudo a acuminado. Inflorescências pedunculadas, pedúnculos $2-13 \mathrm{~cm}$ compr., terminais e axilares, esbranquiçadas, eixo floral capituliforme, 1,5-2,5 $\mathrm{cm}$ compr. Flores esbranquiçadas a esverdeadas, pediceladas, escariosas, subtendidas pelo conjunto de bractéolas, brácteas ca. $3 \mathrm{~mm}$ compr., base truncada, margem inteira, ápice acuminado; bractéolas 3-3,4 $\mathrm{mm}$ compr., ovais; tépalas livres, iguais entre si, elípticas a lanceoladas; ovário ovoide, ca. 0,5 mm; estigma papiloso.

Material selecionado: Parauapebas, Serra Norte, N1, 2.IV.1986, fl, M.P.M. Lima 102 (MG), N5, 606'05”S, $50^{\circ} 07^{\prime} 42$ ”', 755 m, 27.IV.2015; fl, N.F.O. Mota 2910 (MG).

A espécie distribui-se em todas as regiões brasileiras nos domínios fitogeográficos Amazônico, Caatinga, Cerrado e Mata Atlântica (BFG 2015). Serra dos Carajás: Serra Norte: N1 e N5, crescendo sobre solos de canga.
1.2. Alternanthera tenella Colla Mem. Reale Accad. Sci. Torino 33: 131-132, t. 9, f. 1-13. 1829.

Fig. $1 \mathrm{c}-\mathrm{e}$

Subarbusto ereto ou prostrado, ca. 0.2 $\mathrm{m}$ alt.. Folhas subsésseis, pecíolo $0,1-0,2 \mathrm{~cm}$ compr.; limbo foliar $0.7-1,2 \mathrm{~cm}$ compr., $0,2-0,4$ cm larg., elíptico, membranáceo, concolor, verde, glabro em ambas as faces, eucamptódromo, base aguda a cuneada, margem inteira, ápice agudo. Inflorescências sésseis, axilares, esbranquiçadas, capituliformes a espiciformes, 2-3 eixos florais por nó, eixo floral ca. $0,5 \mathrm{~cm}$ compr. Flores esbranquiçadas a esverdeadas, curto-pediceladas, escariosas, sobressaindo da altura das bractéolas; brácteas ca. $2 \mathrm{~mm}$ compr., base truncada, margem inteira, ápice agudo; bractéolas ca. 2,5 mm compr., ovais; tépalas livres, desiguais entre si, ovais ou elípticas; ovário ovoide, ca. $0,4 \mathrm{~mm}$ compr.; estigma piloso.

Material selecionado: Parauapebas [Marabá], N4, $6^{\circ} 00^{\prime}$ 'S, $50^{\circ} 15^{\prime} \mathrm{W}, 600 \mathrm{~m}, 19 . \mathrm{III} .1988$, fl, A.S. L. Silva et al 1897 (MG).

A espécie distribui-se em todas as regiões do Brasil em todos os domínios fitogeográficos (BFG 2015). Serra dos Carajás: Serra Norte: N4, crescendo sobre solos de canga e transição para mata. 


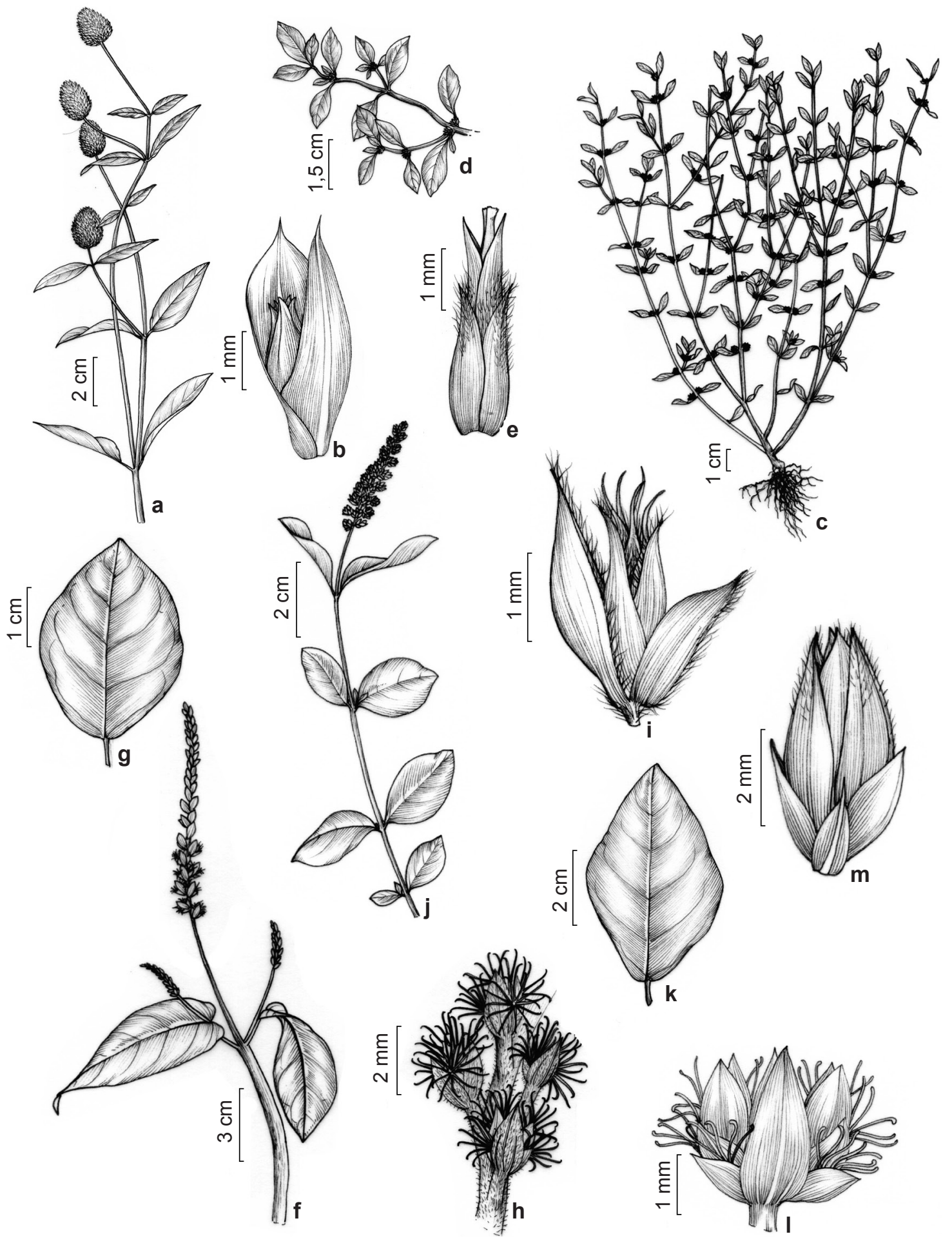

Figura 1 - a-b. Alternanthera dentata - a. hábito; b. flor. c-e. A. tenella - c-hábito; d-ramo; e-flor. f-i. Cyahtula achyranthoides - f. hábito; g. folha; h. tirsos com flores férteis e estéreis; i. flor fértil. j-m. C. prostrata - j. hábito; k. folha; 1. parte apical do ramo da inflorescência (espiga de tirsos); $\mathrm{m}$. flor fértil.

Figure 1 - a-b. Alternanthera dentata - a. habit; b. flower. c-e. A. tenella - c-habit; d-branch; e-flower. f-i. Cyahtula achyranthoides - f. habit; g. leaf; h. thyrsus with sterile and fertile flowers; i. fertile flower. j-m. C. prostrata - j. habit; k. leaf; 1 . apex of inflorescence branch (spike of thyrsi); m. fertile flower. 


\section{Cyathula Blume}

As espécies de Cyathula tem folhas opostas, membranáceas, pecioladas. A inflorescência é terminal, com unidade parcial em dicásio e presença de flores férteis e estéreis, flores estéreis com tépalas modificadas em cerdas unguiculadas. As flores férteis são bissexuadas, com uma bráctea dorsal e duas bractéolas laterais, 5 tépalas livres, escariosas, 5 estames com filetes unidos em tubo curto e com porções livres alternadas com pseudoestaminódios, anteras bitecas, tetraesporangiadas, estigma capitado, estilete igual ou maior que o comprimento do ovário. O fruto é um utrículo indeiscente (Townsed 1993; Senna 2010; BFG 2015). O gênero Cyathula inclui cerca de 25 espécies distribuídas em regiões tropicais do Velho e do Novo Mundo. No Brasil ocorrem duas espécies: C. achyranthoides Moq. e C. prostata Blume distribuídas nos domínios Amazônico, Caatinga, Cerrado, Mata Atlântica, crescendo em áreas antrópicas, caatinga (stricto sensu), campo rupestre, cerrado (lato sensu), floresta ciliar ou de galeria e floresta ombrófila (Senna et al. 2010; BFG 2015).

\section{Chave de identificação das espécies de Cyathula das cangas da Serra dos Carajás}

1. Folhas elípticas, largo-elípticas ou obtusas; tirsos com uma flor fértil e uma flor estéril; flores estéreis com $8-10$ cerdas unguiculadas 2.1. Cyathula achyranthoides

1'. Folhas rômbicas; tirsos com 3 flores férteis e 2 pares de flores estéreis; flores estéreis com 12-20 cerdas unguiculadas 2.2. Cyathula prostrata

2.1. Cyathula achyranthoides (Kunth) Moq. Prodr. 13(2): 326-327. 1849.

Figs. f-i

Subarbusto decumbente a ereto, ca. 0,3 m alt. Folhas pecioladas, pecíolo $0,15-0.3 \mathrm{~cm}$ compr.; limbo foliar 1,5-3 cm compr., 1-2,4 cm larg., elíptico, largo-elíptico ou obtuso, membranáceo, discolor, face adaxial verde, face abaxial verde mais claro, levemente pubescente em ambas as faces, broquidódromo, base arredondada, margem inteira, ápice obtuso. Inflorescências pedunculadas, pedúnculo 3-6 cm compr., eixo floral espiciforme, espiga de tirsos, terminal, 4-7 cm compr. Flores estéreis, uma por tirso, com tépalas modificadas em cerdas unguiculadas, 8-10 cerdas por flor. Flores férteis uma por tirso, branco-esverdeadas, pediceladas, escariosas; bráctea ca. $1 \mathrm{~mm}$ compr., oval, base truncada, margem inteira, ápice agudo a acuminado; bractéolas ca. 1,5 mm compr., ovais; tépalas livres, desiguais, elípticas; ovário oblóide, 0,5-1 mm compr., estilete de tamanho igual ou maior que o comprimento do ovário, estigma capitado a truncado, papiloso.

Material selecionado: Parauapebas, Serra Norte, N4, 6000'00"S, 57¹9'32”'W, 700 m, 22.V.2010, fl, L.V. Costa et al. 914 (BHCB).

A espécie distribui-se em todas as regiões Norte, Nordeste e Sudeste do Brasil nos domínios fitogeográficos Amazônico, Caatinga e Mata Atlântica (BFG 2015). Serra dos Carajás: Serra Norte: N4, crescendo sobre solos de canga e em áreas de transição entre as cangas e matas.
2.2. Cyathula prostrata Blume Bijdr. Fl. Ned. Ind. 11: 549. 1826. Figs. $1 \mathrm{j}-\mathrm{m}$

Subarbusto prostrado a ereto, ca. $0.3 \mathrm{~m}$ alt.. Folhas pecioladas, pecíolo $0,3-0,6 \mathrm{~cm}$ compr.; limbo foliar 2,5-6 cm compr., 1-2,5 cm larg., romboide, membranáceo, discolor, face adaxial verde, face abaxial verde claro, pubescente em ambas as faces, broquidódromo, base obtusa a levemente arredondada, margem inteira, ápice agudo a obtuso. Inflorescências pedunculadas, pedúnculos $2-5 \mathrm{~cm}$ compr., eixo floral $5-10 \mathrm{~cm}$ de comprimento, espiciformes, espigas de tirsos, axilares e terminais. Flores estéreis sendo dois pares de flores estéreis por tirso, com tépalas modificadas em cerdas unguiculadas, 12-20 cerdas por flor. Flores férteis 3 por tirso, branco-esverdeadas, pediceladas e escariosas; brácteas $1,5-2 \mathrm{~mm}$ compr., lanceolada, base truncada, margem inteira, ápice agudo; bractéolas 1-1,5 mm compr., ovais; tépalas livres, desiguais, 2 largo-elípticas, 3 elípticas; filetes unidos; ovário oblongo, $0,5-0,7$ $\mathrm{mm}$ compr. estilete $0,7-10 \mathrm{~mm}$ compr., estigma papiloso.

Material selecionado: Canaã dos Carajás, Serra Sul, S11D, 6027'1,19"S, 50²0'17,7'”, 225 m, 10.XII.2012, $\mathrm{fl}$, I.M.C. Rodrigues et al. 592 (BHCB).

A espécie distribui-se em todas as regiões brasileiras nos domínios Amazônia, Cerrado e Mata Atlântica (BFG 2015). Serra dos Carajás: Serra Sul: S11D, crescendo sobre solos de canga transição para mata. 


\section{Agradecimentos}

Agradecemos ao Instituto Tecnológico Vale e ao Museu Paraense Emílio Goeldi, a estrutura e apoio. Aos curadores dos herbários BHCB, IAN, HCJS, MG e RB, a disponibilização de material para a análise. Ao Dr. Pedro Viana e Dra. Ana Maria Giulietti, coordenadores do projeto "Flora de Carajás", o convite. Ao projeto objeto do convênio MPEG/ITV/ FADESP (01205.000250/2014-10) e ao projeto aprovado pelo CNPq (processo 455505/2014-4), o financiamento.

\section{Referências}

APG IV (2016). An update of the Angiosperm Phylogeny Group classification for the orders and families of flowering plants. Botanical Journal of the Linnean Society 181: 1-20p.

BFG - The Brazil Flora Group (2015) Growing knowledge: an overview of seed plant diversity in Brazil. Rodriguésia 66: 1085-1113.
Cronquist A \& Thorne RF (1994) Nomenclatural and taxonomic history. In: Behnke HD \& Mabry TJ (eds.) Caryophyllales: evolution and systematics. Springer, New York. Pp. 87-121.

Kadereit G, Borsch T, Weising K \& Freitag H (2004) Phylogeny of Amaranthaceae and Chenopodiaceae and the evolution of $\mathrm{C} 4$ photosynthesis. International Journal of Plant Sciences 164: 956986.

Kühn U (1993) Chenopodiaceae. In: Kubitzki K (ed.) The families and genera of vascular plants. Vol 5 . Springer-Verlag, Berlin. Pp. 253-280.

Senna L, Giulietti AM \& Rapini A (2010) Flora da Bahia: Amaranthaceae - Amaranthoideae e Gomphrenoideae. Sitientibus 10: 3-73.

Senna L (2015) Revisão taxonômica das espécies brasileiras de Alternanthera Forsk. (Amaranthaceae Juss.). Tese de Doutorado. Universidade Estadual de Feira de Santana, Feira de Santana. 360 p.

Towsend C (1993) Amaranthaceae. In: Kubitzki K (ed.) The families and genera of vascular plants. Vol 5. Springer-Verlag, Berlin. Pp. 253-280.

\section{Lista de exsicatas}

Costa LV 914 (2.1). Lima MPM 102 (1.1). Mota NFO 2910 (1.1). Silva ASL 1897 (1.2). Rodrigues IMC 592 (2.2). 